$$
\text { Pontifícia }_{\text {Universidade }} \text { Católica }_{\text {do Rio de Janeiro }}
$$

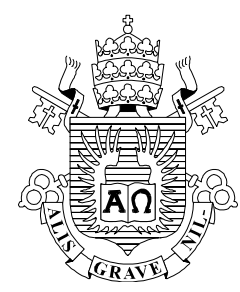

Nivaldo de Barros e Silva Neto

\title{
Assegurando Adequação Estratégica do Trade Marketing Foco em Empresas de Bens de Consumo
}

Dissertação apresentada ao Programa de Pós-Graduação em Administração de empresas da PUC-RJ como requisito parcial para obtenção do título de Mestre em Administração de Empresas.

Orientadora: Teresia Diana Lewe van Aduard de Macedo Soares,

Rio de Janeiro

Março de 2009 


\section{Pontifícia Universidade C $_{\text {atólica }}$ \\ DO RIO DE JANEIRO}

\section{Nivaldo de Barros e Silva Neto}

\section{Assegurando Adequação Estratégica do Trade Marketing \\ Foco em Empresas de Bens de Consumo}

Dissertação apresentada ao Programa de Pós-Graduação em Administração de empresas da PUC-RJ como requisito parcial para obtenção do título de Mestre em Administração de Empresas. Aprovada pela Comissão Examinadora abaixo assinada.

Prof. Teresia Diana Lewe van Aduard de Macedo Soares

Orientadora - Presidente

Departamento de Administração - PUC - RJ

Prof. Sandra Regina da Rocha Pinto

Departamento de Administração - PUC - RJ

Prof. Cláudio Pitassi

IBEMEC - RJ

Prof. Nizar Messari

Vice- Decano de Pós-Graduação do CCS

Rio de Janeiro, 12 de março de 2009 
Todos os direitos reservados. É proibida a reprodução total ou parcial do trabalho sem autorização da universidade, do autor e da orientadora.

\section{Nivaldo de Barros e Silva Neto}

Graduou-se em Engenharia Civil pela Universidade Federal de Pernambuco em 1998. Concluiu o curso de MBA Executivo na Fundação Dom Cabral em Minas Gerais em 2006. No âmbito profissional atuou em empresas multinacionais como Unilever e L'Oréal, sempre trabalhando na área comercial e de Trade Marketing. Atualmente ocupa o cargo de Diretor de Trade Marketing da divisão de Produtos Grande Público da L’Oréal Brasil.

Ficha Catalográfica

Silva Neto, Nivaldo de Barros e

Assegurando adequação estratégica do trade marketing: foco em empresas de bens de consumo / Nivaldo de Barros e Silva Neto ; orientadora: Teresia Diana Lewe van Aduard de Macedo Soares. -2009.

150 f. : il. ; $30 \mathrm{~cm}$

Dissertação (Mestrado em Administração)Pontifícia Universidade Católica do Rio de Janeiro, Rio de Janeiro, 2009.

Inclui bibliografia

1. Administração - Teses. 2. Trade marketing. 3. Bens de consumo. 4. Varejo. 5. Canais de Distribuição. 6. Estratégia. I. Soares, Teresia Diana Lewe van Aduard de Macedo. II. Pontifícia Universidade Católica do Rio de Janeiro. Departamento de Administração. III. Título. 
Para Mariana.

Seu apoio, carinho e incentivo foram fundamentais, sem eles eu não teria conseguido chegar ao final desta caminhada.

Te amo. 


\section{Agradecimentos}

Em primeiro lugar agradeço a Deus por ter me permitido realizar este trabalho, me dando saúde e todos os recursos necessários durante este longo caminho. Peço a Ele que, terminada esta etapa, me dê forças para conseguir compartilhar todo o aprendizado e experiência adquirida.

A meus pais, Nivaldo e Juliêta, pelo carinho e incentivo que sempre me deram e por todas as condições oferecidas para que eu pudesse ter uma formação acadêmica de alto nível. Aos meus irmãos, Leandro, Lenôra, Leonardo e Leila e a minha avó, Berenice, que foram responsáveis por grande parte da formação do meu caráter e personalidade como ser humano. Todas as conquistas que tenho alcançado em minha vida profissional e acadêmica devo a esta família maravilhosa que Deus me deu.

À minha orientadora Diana Macedo Soares que sempre me fez buscar a excelência na construção do trabalho. Sua experiência, paciência e atenção aos detalhes foram fundamentais no resultado final obtido.

A todos os professores que durante o período do curso me passaram seus conhecimentos e experiências. A todos os funcionários da PUC que sempre possibilitaram um ambiente propício para o estudo.

Aos colegas e amigos de turma que fizeram com que o curso se tornasse um momento agradável de crescimento pessoal e profissional. Em especial aos membros do "Dream Team" (André Neiva, André Basile, Filipe Dantas e Juarez Sigwalt), mais do que colegas de turma nos tornamos grandes amigos.

A todos os companheiros de trabalho que ao longo da minha vida contribuíram para minha formação profissional. Em especial agradeço a Willian D'Andrea que foi o grande orientador da minha carreira na área de Trade Marketing, sua experiência foi fundamental na minha formação como profissional.

Finalmente a todos que responderam o questionário permitindo que eu conseguisse um rico material a ser utilizado no presente estudo. 


\section{RESUMO}

Silva Neto, Nivaldo de Barros e; Macedo-Soares, Teresia Diana Lewe van Aduard de. Assegurando Adequação Estratégica do Trade Marketing: Foco em empresas de bens de consumo. Rio de Janeiro, 2009. 150p. Dissertação de Mestrado - Departamento de Administração, Pontifícia Universidade Católica do Rio de Janeiro.

A competitividade no mercado de bens de consumo não duráveis vem aumentando nos últimos anos. Empresas que atuam neste segmento enfrentam, a cada dia, maiores dificuldades para diferenciar seus produtos frente a seus concorrentes. O novo cenário competitivo fez com que as indústrias entendessem a importância dos clientes que distribuem seus produtos ao consumidor final, sejam eles varejistas ou atacadistas e distribuidores. A construção de uma boa relação comercial com tais elementos da cadeia produtiva tornou-se um dos principais diferenciais competitivos para as indústrias do mercado de bens de consumo. Em especial, tornou-se importante as estratégias adotadas para atuação dentro dos pontos de venda, local onde efetivamente são realizadas as compras dos produtos. Para suprir de forma adequada estas novas necessidades mercadológicas, as empresas também tiveram que modificar suas estruturas organizacionais. Estas mudanças fizeram surgir uma nova área dentro das organizações denominada: TRADE MARKETING. O Trade Marketing surge com o objetivo de conseguir unificar as estratégias construídas pelas áreas de marketing e sua efetiva implementação dentro do ponto de venda. As estratégias construídas são implementadas pelas áreas de vendas, as quais muitas vezes não estão de acordo com as mesmas. O Trade Marketing surge para tentar diminuir o distanciamento entre a área de vendas e a área de marketing. A presente pesquisa buscou identificar quais fatores colaboram e quais dificultam a adequação estratégica da área de Trade Marketing dentro das organizações. Através da utilização do ferramental de análise estratégica Genérico Integrativo de MacedoSoares (2001) o autor realiza uma pesquisa com executivos do setor de maneira a encontrar os atributos que garantam a adequação da área de Trade Marketing à estratégia de suas empresas.

\section{Palavras Chave}

Trade Marketing; Bens de Consumo; Varejo; Canais de Distribuição; Estratégia. 


\section{ABSTRACT}

Silva Neto, Nivaldo de Barros e; Macedo-Soares, Teresia Diana Lewe van Aduard de. Guaranteeing the Strategic Fit of Trade Marketing: Focusing firms in the Consumer Goods Market. Rio de Janeiro, 2009. 150p. Msc Dissertation - Departamento de Administração, Pontifícia Universidade Católica do Rio de Janeiro.

Competition in the non-durable consumer goods market has been growing apace in recent years, and companies that operate in this segment have been finding it increasingly difficult to differentiate their products from those of their competitors. The new competitive scenario has made industries realize the importance of customers who distribute their products to the final consumer, whether they be retailers (supermarkets, drugstores, convenience stores) or wholesalers and distributors. Having a good commercial relationship with these elements of the production chain now constitutes a major competitive differential for industries in the mass consumer goods market. Operational strategies at points of sale - where product purchases effectively occur - have become particularly important. In order to fulfill these new market needs, firms have also been obliged to modify their organizational structures. These changes have led to the appearance of a new area in organizations, known as TRADE MARKETING. Trade Marketing's aim is to unify strategies developed by marketing areas and effectively implement them at points of sale. These strategies are implemented by sales areas and the latter do not always agree with strategies proposed by marketing areas, as they are not aligned with customer expectations. Trade Marketing's function is to bring sales and marketing areas closer together. Despite this new area's growing strategic importance, there are few scientific studies devoted to this theme. The present research sought to identify the factors that facilitate or hinder the Trade Marketing area's strategic fit. Using Macedo Soares' (2001) Generic Integrative model for strategic analysis, the author performed a survey of executives of the sector in order to discover a list of attributes that assure the strategic fit of their companies' Trade Marketing areas.

\section{Keywords}

Trade Marketing; Consumer Goods; Retail; Distribution Channels; Strategy 


\section{Sumário}

1. Introdução 13

1.1. O problema 14

1.2. Objetivo 15

1.3. Relevância do estudo 15

1.4. Delimitação do estudo 16

$\begin{array}{ll}\text { 1.5. } & \text { Estrutura da dissertação } \\ \end{array}$

2. Referencial Teórico 19

2.1. Conceitos centrais 19

2.2. Definições de Trade Marketing 22

2.3. O surgimento do Trade Marketing nas organizações 24

2.4. A evolução do Trade Marketing dentro das empresas 32

2.5. Posicionamento teórico - Metodologia de Análise Estratégica 36

3. Metodologia 48

3.1. Tipo de pesquisa 48

3.2. Universo e amostra - Seleção de Sujeitos 49

3.2.1. Perfil dos Respondentes 51

3.3. Coleta de dados 53

3.4. Tratamento dos dados 55

3.5. Limitações do método 55

4. Resultados 57

4.1. Caracterização das estratégias das empresas pesquisadas 58

4.2. Implicações estratégicas dos fatores organizacionais 64

4.3. Implicações estratégicas dos fatores organizacionais pertinentes a $\begin{array}{ll}\text { área de Trade Marketing } & 71\end{array}$

5. Discussão e Considerações Finais 81

5.1. Avaliação da adequação estratégica do Trade Marketing 81

5.2. Validação dos fatores organizacionais desejáveis para assegurar a adequação estratégica da área de Trade Marketing 84

5.3. Considerações Finais 110 
6. Referências Bibliográficas

7. Anexos 


\section{Listas de Figuras e Quadros}

\section{Figuras}

Figura 1 - Mentalidade das empresas versus mentalidade dos consumidores

Figura 2 - Evolução das Fases de implementação de Trade Marketing 34 Figura 3: Modelo Gl de Macedo-Soares em Macedo-Soares e Lucas (1996)

Figura 4: A função de Trade Marketing na organização

\section{Quadros}

Quadro 1 - Delimitação da Pesquisa

Quadro 2 - Lista de Atributos Necessários / Desejáveis para cada variável principal buscando-se a adequação estratégica da área de Trade Marketing. Adaptada de Macedo-Soares (apud Macedo-Soares e Figueira, 2007) no caso de empresas com estratégia orientada para o cliente no setor de bens de consumo. Em negrito são colocados os atributos mais específicos ao Trade Marketing.

Quadro 3 - Lista de Empresas Participantes da Pesquisa 50

Quadro 4 - Distribuição dos respondentes de acordo com a função que ocupam atualmente em suas empresas.

Quadro 5 - Detalhamento do tempo de experiência profissional dos Respondentes

Quadro 6 - Distribuição dos respondentes por departamento dentro das organizações

Quadro 7 - Perfil dos Respondentes - Sexo e Formação Superior

Quadro 8 - Distribuição das questões de acordo com a classificação dos atributos desejáveis indicados no posicionamento teórico.

Quadro 9 - Lista das Empresas da Pesquisa - Produtos e Estratégia (Missão / Visão)

Quadro 10 - Respostas das questões 2.01 a 2.03.

Quadro 11 - Respostas das questões 2.04 a 2.08.

Quadro 12 - Respostas da questão 2.09. 
Quadro 14 - Respostas da questão 3.01. 64

Quadro 15 - Respostas das questões 3.04 e 3.06 . 65

Quadro 16 - Respostas das questões 3.03 e 3.05 . 65

Quadro 17 - Respostas da questão 3.12. 66

Quadro 18 - Respostas das questões 5.01 e 5.02 . 66

Quadro 19 - Respostas das questões 6.01 e 6.04 . 67

Quadro 20 - Respostas da questão 7.01. 67

Quadro 21 - Respostas das questões 8.03 a 8.06 . 68

Quadro 22 - Respostas das questões 9.01 a 9.03 . 69

Quadro 23 - Respostas das questões 10.01 a 10.06 e $10.09 \quad 70$

Quadro 24 - Classificação dos fatores organizacionais, não associados diretamente a área de Trade Marketing, mas que possam se constituir em forças ou fraquezas para suportar a área. $\quad 71$

Quadro 25 - Respostas da questão 3.02. 72

Quadro 26 - Respostas das questões 3.09 e 3.10.

Quadro 27 - Respostas das questões 4.01 e 4.04 . 73

Quadro 28 - Respostas das questões 4.11 e 4.12 . 73

Quadro 29 - Respostas das questões 5.03 a 5.08 . 74

Quadro 30 - Respostas das questões 5.04 e 5.05.

Quadro 31 - Respostas das questões 6.05 e 6.06.

Quadro 32 - Respostas das questões 7.02, 7.03 e 7.09.

Quadro 33 - Respostas das questões 8.01 e 8.02 . 76

Quadro 34 - Respostas da questão 9.04. 77

Quadro 35 - Respostas das questões 10.07 e 10.08 . 77

Quadro 36 - Respostas da questão 10.10. 77

Quadro 37 - Respostas da questão 11.01. 78

Quadro 38 - Respostas da questão 12.01 . 78

Quadro 39 - Respostas das questões 14.01 a $14.04 \quad 79$

Quadro 40 - Classificação dos fatores organizacionais pertinentes à área de Trade Marketing identificados como forças e fraquezas a luz da estratégia das empresas pesquisadas $\quad 80$

Quadro 41 - Respostas da questão 3.08

Quadro 42 - Respostas das questões 3.09 e $3.10 \quad 86$

Quadro 43 - Respostas das questões 3.09 e $3.10 \quad 86$ 
Quadro 44 - Respostas das questões 4.01 a $4.04 \quad 87$

Quadro 45 - Respostas das questões 4.05 a $4.07 \quad 89$

Quadro 46 - Respostas da questão $4.09 \quad 91$

Quadro 47 - Respostas das questões 7.02 a $7.10 \quad 95$

Quadro 48 - Respostas da questão $9.05 \quad 98$

Quadro 49 - Respostas da questão $9.06 \quad 98$

Quadro 50 - Respostas das questões 11.02, 11.05 e 11.06

Quadro 51 - Respostas das questões 11.03-11.04 102

Quadro 52 - Respostas das questões 12.01-12.04 105

Quadro 53 - Respostas das questões 14.01-14.04 107

Quadro 54 - Respostas das questões 14.05-14.06 108

Quadro 55 - Lista FINAL de Atributos Necessários / Desejáveis para cada variável principal buscando-se a adequação estratégica da área de Trade Marketing, no caso de empresas com estratégia orientada para o cliente no setor de bens de consumo no Brasil. 110

Quadro 56 - Atividades da área de Trade Marketing 115 Quadro 57 - Temas para serem abordados em treinamentos para área de Trade Marketing.

Quadro 58 - Informações para sistemas de informação direcionados a área de Trade Marketing. 